\title{
Evaluation of Individualized Information Service Capability Based on DHNN
}

\author{
Wang Jian \\ School of Information \\ Central University of Finance and Economics \\ Beijing, China \\ wanderingful@126.com
}

\author{
Zhang Yuanyuan \\ School of Information \\ Central University of Finance and Economics \\ Beijing, China \\ wanderingful@126.com
}

\begin{abstract}
Information service system providing service according to the specific requirements of user, or user's personnel characteristics like subject, preference and usage etc. In university,different sutudent have their own individualized information requirements, so the services provided by library must become initiatively though customization, and push function,which means a kind of customer-center .In This paper discusses the purpose and meaning of individualized information service of library, and also the index system of service performance evaluation are investigated. In view of the uncertainty problems in individualized information service capability evaluation, this article develops an evaluation model based on Discrete Hopfield Neural Network (DHNN). The paper also gives a concrete algorithm. The experiment result shows that the proposed method can resolve the uncertainty problem in evaluation process effectively. The feasibility of proposed method is testified also.
\end{abstract}

Keywords-Individualized Information Service; Capability Evaluation; DHNN; Recommendation System; Index of individualized information service

\section{INTRODUCTION}

Individualized information service in the information age means providing service that user may need initiatively though customization, system recommendation and push function, according to the specific requirements of user, or user's personnel characteristics like subject, preference and usage etc. It is a kind of customer-center service mode [1]

The appearance of this kind of service mode has changed the service mode of library in the old days that "whatever we offer, you'll accept", created the information service mode with mainly characteristics of individuality and interactivity that "whatever you need, we'll offer", thus individualized information service becomes the hot topic of library research and study both in China and abroad.

However, research at present mainly emphasizes on the issues about individualized information service theory, service technology, service mode, service system and the restriction factors exist in the service practice, ability evaluation for the library individualized information service hasn't formed a unified evaluation target system [2-4], and scientific evaluation methods hasn't been found, which constrains the development of individualized information service. Therefore, it's urgent to adopt objective and reasonable quantized method to evaluate the ability of individualized information service, find out the existing issues and weak links and make effective improvement measures; these will have important practical significance for the improvement of the individualized information service ability.

This article comes up with an individualized information service capability evaluation model basing on the Discrete Hopfield Neural Network (DHNN), simulation data that expert used for evaluate service grade is used in research to test and evaluate the method.

\section{DHNN MODE}

Hopfield network is the most typical two-value feedback network model. It is one of the most models studied by people at present. The output of neuron only takes 1 and -1 , separately indicating the neural is in inhibition and activation, and thus it can be called Discrete Hopfield Neural Network. DHNN is formed by monolayer with common neurons, and it is a kind of autoassociative neural network with study function, which can complete restriction optimization and associative memory etc. functions [5-7].

Suppose one DHNN consists of three neurons, with the structure shows in Fig .1.

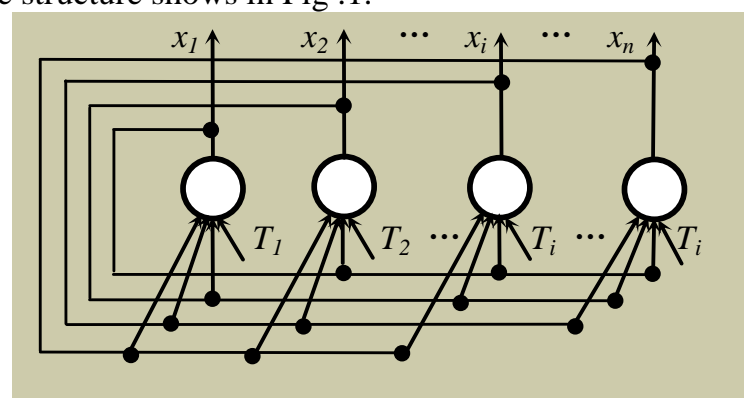

Figure 1.Hopfield Neural Network composed by three neurons

We can see from the structure of the DHNN that: it is a kind of two-value non-linear dynamical system which has multiple inputs and threshold values. In dynamical system, stable state can be interpreted as certain type of energy function whose energy value continuously 
decrease during the movement process of the system, and is in the minimum value at last. Designing weight coefficient matrix of Hopfield Neural Network can realize stabilization of the network.

\section{EVALUATION INDEX SYSTEM OF INDIVIDUALIZED INFORMATION SERVICE ABILITY}

As evaluation system of the individualized information service ability is a complex system, issues like randomness, fuzziness of the evaluation factors and imperfect of index statistical data will be found in the evaluation process, these uncertain issues call for the experts evaluate comprehensively for the individualized information service ability, according to their own experience and knowledge and the own qualitative and quantitative nature in index system.

Considering complexity and particularity of the individualized information service, evaluation for the library individualized information service ability can be done from service infrastructure and environment, information resource, service technology and mode, service effect four aspects [8][9].

TABLE1.FIVE INDEX OF INDIVIDUALIZED INFORMATION SERVICE ABILITY EVALUATION

\begin{tabular}{|c|c|c|}
\hline Grade 1 Index & Grade 2 Index & Details of evaluation \\
\hline \multirow{5}{*}{$\begin{array}{l}\text { service infrastructure and } \\
\text { environment } \\
\text { A1 }\end{array}$} & $\begin{array}{l}\text { Individualized service space } \\
\text { A11 }\end{array}$ & $\begin{array}{l}\text { Individual learning space, Group system working space, } \\
\text { information service counter, rest area etc. }\end{array}$ \\
\hline & individualized service workstation A12 & $\begin{array}{l}\text { Hardware resources: PC, high-end workstation, printer, } \\
\text { scanner etc. }\end{array}$ \\
\hline & $\begin{array}{l}\text { Individualized information service system } \\
\text { construction } \\
\text { A13 }\end{array}$ & $\begin{array}{l}\text { Multilevel information service; dynamics and auto } \\
\text { update ability; utilizability, operability of system, affinity of } \\
\text { interface, storage of data information and organizational } \\
\text { mode in system etc. }\end{array}$ \\
\hline & $\begin{array}{l}\text { Structure and competence of service staff } \\
\qquad \text { A14 }\end{array}$ & $\begin{array}{l}\text { Allocation proportion of staff; reservation of related } \\
\text { staff; knowledge capacity, innovation capability, } \\
\text { communication and cooperation capability and professional } \\
\text { ethics of staff }\end{array}$ \\
\hline & $\begin{array}{l}\text { Condition of user need } \\
\text { A15 }\end{array}$ & $\begin{array}{l}\text { Need extent for individualized service of user and } \\
\text { awareness of accepting the individualized service }\end{array}$ \\
\hline \multirow{6}{*}{$\begin{array}{l}\text { Information resource } \\
\qquad \mathrm{A} 2\end{array}$} & $\begin{array}{l}\text { Comprehensiveness of information recourse } \\
\qquad \text { A21 }\end{array}$ & $\begin{array}{l}\text { Volume of literature, rate of security, volume of per- } \\
\text { capita contributed new literatures, proportion and quantity } \\
\text { of data bank of each type }\end{array}$ \\
\hline & Pertinence of information resource A22 & $\begin{array}{l}\text { Digital resource satisfied by specific user group or not, } \\
\text { deepness and wideness of resource meet user's professional } \\
\text { requirements or not }\end{array}$ \\
\hline & $\begin{array}{l}\text { Pertinence of information resource } \\
\qquad \text { A23 }\end{array}$ & $\begin{array}{l}\text { Digital resource satisfied by specific user group or not, } \\
\text { depth and scope of resource meet user's professional } \\
\text { requirements or not }\end{array}$ \\
\hline & $\begin{array}{l}\text { Authority of information resource } \\
\qquad \text { A24 }\end{array}$ & $\begin{array}{l}\text { Digital resource selected and processed by professional } \\
\text { staff in accordance with related standard or not, whether } \\
\text { evaluated and approved by experts in the same field or not }\end{array}$ \\
\hline & Peculiarity of information resource A25 & $\begin{array}{l}\text { Digital resource whether has its own characteristic, } \\
\text { development of self-build data bank with individual } \\
\text { characteristic }\end{array}$ \\
\hline & Timeliness of information resource A26 & $\begin{array}{l}\text { Newness and timeliness of literature resource, digital } \\
\text { resource, update cycle and speed of self-build data bank etc. }\end{array}$ \\
\hline \multirow{5}{*}{$\begin{array}{l}\text { Service technology } \\
\text { and mode } \\
\text { A3 }\end{array}$} & $\begin{array}{l}\text { Information acquisition and filtration } \\
\text { technology } \\
\text { A31 }\end{array}$ & $\begin{array}{l}\text { User demand whether can be acquired } \\
\text { comprehensively, rapidly and accurately or not, extracting } \\
\text { the literature and resource that most corresponding to user's } \\
\text { demand though own international mechanism }\end{array}$ \\
\hline & $\begin{array}{l}\text { Feature extraction and disposal technology } \\
\qquad \mathrm{A} 32\end{array}$ & $\begin{array}{l}\text { Whether can extract user's feature vector accurately and } \\
\text { classify to the user characteristic according to user's } \\
\text { demand; Collecting external information according to user } \\
\text { feature and dispose, organize and store it etc. }\end{array}$ \\
\hline & $\begin{array}{c}\text { Information mining technology } \\
\mathrm{A} 33 \\
\end{array}$ & $\begin{array}{c}\text { Ability of association analysis, cluster analysis, } \\
\text { classification, prediction, variance analysis. }\end{array}$ \\
\hline & $\begin{array}{c}\text { Information customization and push } \\
\text { technology } \\
\text { A34 }\end{array}$ & $\begin{array}{l}\text { Convenience and flexibility of customization process; } \\
\text { Automation, intelligent extent, and efficiency of data push }\end{array}$ \\
\hline & $\begin{array}{l}\text { Personal privacy protection technology } \\
\text { A35 }\end{array}$ & $\begin{array}{l}\text { Whether personnel privacy protection mechanism and } \\
\text { policy be considered in the service, whether key technology } \\
\text { inset in service technology }\end{array}$ \\
\hline \multirow{2}{*}{$\begin{array}{l}\text { Service effect } \\
\quad \text { A4 }\end{array}$} & $\begin{array}{l}\text { Satisfactory degree on service quality } \\
\text { A41 }\end{array}$ & $\begin{array}{l}\text { User's satisfactory degree on the information volume, } \\
\text { creativeness of information, timeliness, pertinence and } \\
\text { availability of service in the process of individualized } \\
\text { service. }\end{array}$ \\
\hline & $\begin{array}{l}\text { Satisfactory degree on service benefit } \\
\qquad \text { A } 42\end{array}$ & $\begin{array}{l}\text { Use ratio, realized value (compare the value and created } \\
\text { by service to consumption produced by achievement), social } \\
\text { response (compare social response after service to created } \\
\text { benefit) of individualized service. }\end{array}$ \\
\hline
\end{tabular}


In this article, we divide the ability of individualized information service into five grades: very strong (I), stronger (II), general (III), worse (IV) and worst (V). According to the research and evaluation to the individualized information service ability of 20 colleges and universities, combine with associative memory ability of DHNN, build DHNN library individualized information service ability evolution mode ${ }^{[10]}$.

In the realization process, evolution index that several typical classification grades corresponding to is designed as the balance point of DHNN, study process of Hopfield neural network is the process that typical classification grades evaluation index gradually approach to Hopfield network balance point. After the

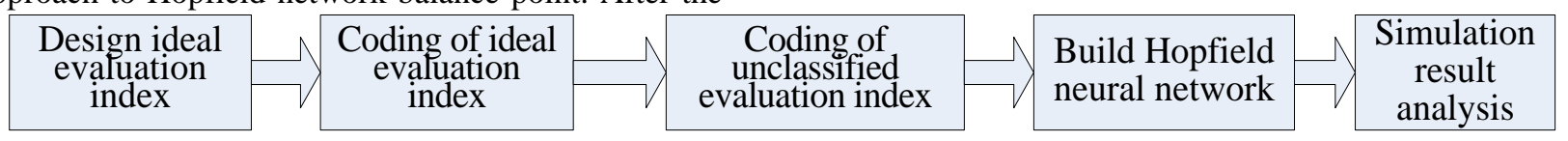

Figure 2.Flow chart of model building

\section{A. Index Coding}

This article studies the relationship between the ability and index of individualized information service ability of 20 colleges and universities libraries. Make study completed, the balance point of Hopfield neural network is the evaluation index of every classification grade that corresponding to. When evaluation index of enterprise innovation that need to be classified is outputted, Hopfield neural network will use its ability of associative memory to gradually approach to the certain stored balance point, till the state no longer changes, this balance point corresponding to is the classification grade that we seek for.

\section{EXPERIMENT STEP AND RESULT ANALYSIS}

Test process shows in Fig .2
TABLE2.FIVE GRADE IDEAL EVOLUTION INDEXES

\begin{tabular}{|c|c|c|c|c|c|c|c|c|c|c|c|c|c|c|c|c|c|c|}
\hline & A11 & A12 & A13 & A14 & A15 & A21 & A22 & A23 & A24 & A25 & A26 & A31 & A32 & A33 & A34 & A35 & A41 & A42 \\
\hline $\mathrm{I}$ & 93 & 91 & 92 & 94 & 91 & 95 & 93 & 92 & 92 & 92 & 93 & 94 & 94 & 95 & 92 & 95 & 93 & 92 \\
\hline II & 77 & 78 & 81 & 78 & 82 & 83 & 79 & 77 & 82 & 80 & 82 & 81 & 79 & 80 & 83 & 82 & 80 & 82 \\
\hline III & 63 & 67 & 64 & 63 & 67 & 64 & 66 & 67 & 68 & 67 & 65 & 64 & 66 & 65 & 64 & 63 & 67 & 64 \\
\hline IV & 45 & 49 & 51 & 55 & 55 & 49 & 46 & 51 & 52 & 51 & 48 & 50 & 52 & 54 & 50 & 49 & 51 & 53 \\
\hline $\mathrm{V}$ & 27 & 33 & 32 & 29 & 27 & 33 & 30 & 26 & 31 & 34 & 29 & 30 & 35 & 34 & 33 & 30 & 31 & 32 \\
\hline
\end{tabular}

As the sate of DHNN neural network only has 1 and -1 two kinds, when the evaluation index reflected as the state of neural state, coding is needed. Coding rules are: when greater than or equal to certain grade index value, the neural state that corresponding to shall be set
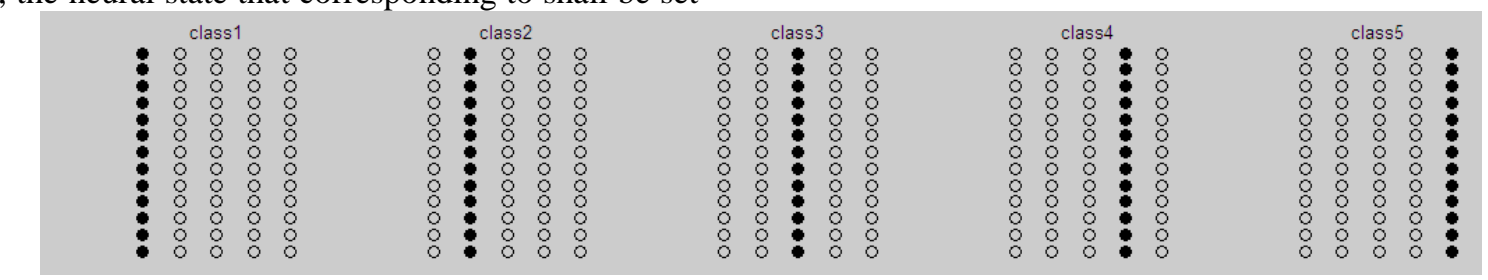

as 1 , or will be -1 . Ideal 5 grade evaluation indexes are listed in Fig .3,* shows the state of neural is 1, means greater than or equal to the ideal evaluation index that corresponding to the grade, otherwise shall use $\mathrm{x}$. the evolution index average value corresponding to every grade sample as the ideal evolution index of each grade, namely, as the balance point of Hopfield neural network [10], shown in Table 2.

Figure 3. Ideal evolution index codes

Five unclassified individualized information service evolution indexes are shown in the table.3, getting the corresponding codes are shown in the second line of Fig .4 according to the above coding rules.

TABLE 3. FIVE UNCLASSIFIED GRADE EVOLUTION INDEXES

\begin{tabular}{|l|l|l|l|l|l|l|l|l|l|l|l|l|l|l|l|l|l|l|}
\hline & $\mathbf{A}_{\mathbf{1 1}}$ & $\mathbf{A}_{\mathbf{1 2}}$ & $\mathbf{A}_{\mathbf{1 3}}$ & $\mathbf{A}_{\mathbf{1 4}}$ & $\mathbf{A}_{\mathbf{1 5}}$ & $\mathbf{A}_{\mathbf{2 1}}$ & $\mathbf{A}_{\mathbf{2 2}}$ & $\mathbf{A}_{\mathbf{2 3}}$ & $\mathbf{A}_{\mathbf{2 4}}$ & $\mathbf{A}_{\mathbf{2 5}}$ & $\mathbf{A}_{\mathbf{2 6}}$ & $\mathbf{A}_{\mathbf{3 1}}$ & $\mathbf{A}_{\mathbf{3 2}}$ & $\mathbf{A}_{\mathbf{3 3}}$ & $\mathbf{A}_{\mathbf{3 4}}$ & $\mathbf{A}_{\mathbf{3 5}}$ & $\mathbf{A}_{\mathbf{4 1}}$ & $\mathbf{A}_{\mathbf{4 2}}$ \\
\hline 1 & 96 & 92 & 85 & 89 & 93 & 87 & 94 & 76 & 98 & 94 & 97 & 88 & 84 & 78 & 93 & 92 & 91 & 88 \\
\hline 2 & 70 & 88 & 75 & 82 & 96 & 79 & 89 & 80 & 84 & 85 & 83 & 81 & 77 & 91 & 85 & 86 & 73 & 87 \\
\hline 3 & 60 & 75 & 68 & 67 & 57 & 74 & 76 & 83 & 69 & 75 & 64 & 68 & 69 & 70 & 53 & 69 & 67 & 64 \\
\hline 4 & 45 & 49 & 51 & 55 & 55 & 49 & 46 & 51 & 52 & 51 & 48 & 50 & 52 & 54 & 50 & 49 & 51 & 53 \\
\hline 5 & 27 & 33 & 32 & 29 & 27 & 33 & 30 & 26 & 31 & 34 & 29 & 30 & 35 & 34 & 33 & 30 & 31 & 32 \\
\hline
\end{tabular}




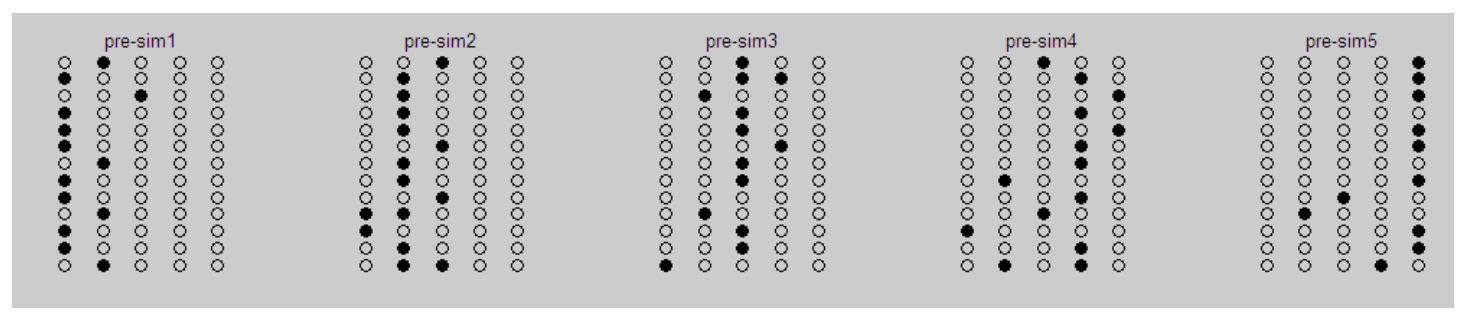

Figure 4.Unclassified evolution index code

\section{B. Experimental Results Analysis}

After designing five ideal grades evaluation indexes and codes, DHNN can be built using MATLAB own neural network toolbox functions, after that, Using the five unclassified individual information service evaluation index codes as the output of Hopfield neural network, after certain times studies, simulation result will be achieved. Comparing the simulation result to the real grade, reasonable evaluation for the model can be made.

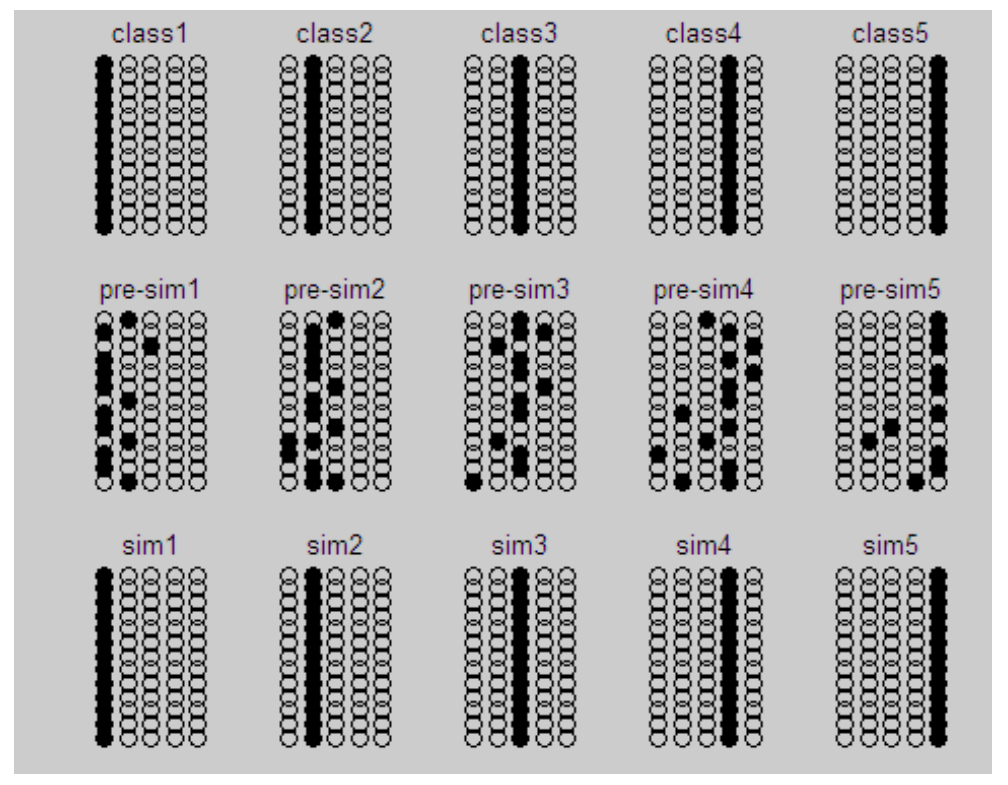

Figure 5. Classification result recognized by DHNN

\section{REFERENCES}

[1] Information on http: / /www.dlib.org / dlib / april00 /mistlebauer/04mistlebauer.html.

[2] C.Jayawardana, K.P.Hewagamage, M.Hirakawa: Information and Technology and Libraries: Vol. 20 -4(2001).

[3] J.J. Hopfield: Proceedings National Academy of Sciences Vol. 79 (1982), p. 2454-2458.

[4] W.Y. CHEN: Journal of Systems Science and System s Engineering Vol. 4(1997), p.389-395.
Simulation results are showed in Fig .5, among these, the first line is corresponding to Fig .3, showing five ideal grade evaluation index codes; the second line is corresponding to Fig .4, showing individual classification evaluation index codes; the third line is the results that designed for DHNN classification; from Fig .5 we can see that the designed DHNN can classify effectively, thus can make objective and impartial evaluation for individual information service ability. 